health, technology and agriculture took place during the recovery from the "little" ice age after 1700 (p.308). For the historian such connections - like the attempt to link unsettled meteorological times with rebellion and revolt (p.196) - require much more precise chains of evidence and reasoning. How much store can one set by them if rebellions also occur in benign ages or if non-climatic influences seem quite sufficient to explain, say, the union of England with Scotland? A great deal more work will be needed before such arguments gain wide acceptance.

In the meantime, Lamb's remains the best introduction to the subject - erudite, wide-ranging and consistently thought provoking. The book is not always as clearly written as it might be; the detail is sometimes overwhelming and contradictory; and there are repetitions and reversals of chronology (for example on p.237) which may confuse. But the call for further research, promising important discoveries about the nature of climate and its effects, is eloquently delivered. In particular, Lamb notes, it is essential to collate the historical research that has begun, and to shape current investigations into a coherent and unified effort. Already the studies of the past have revealed some remarkably consistent cycles and such extraordinary phenomena as the 0.75 correlation between the number of days with southwesterly surface wind in London

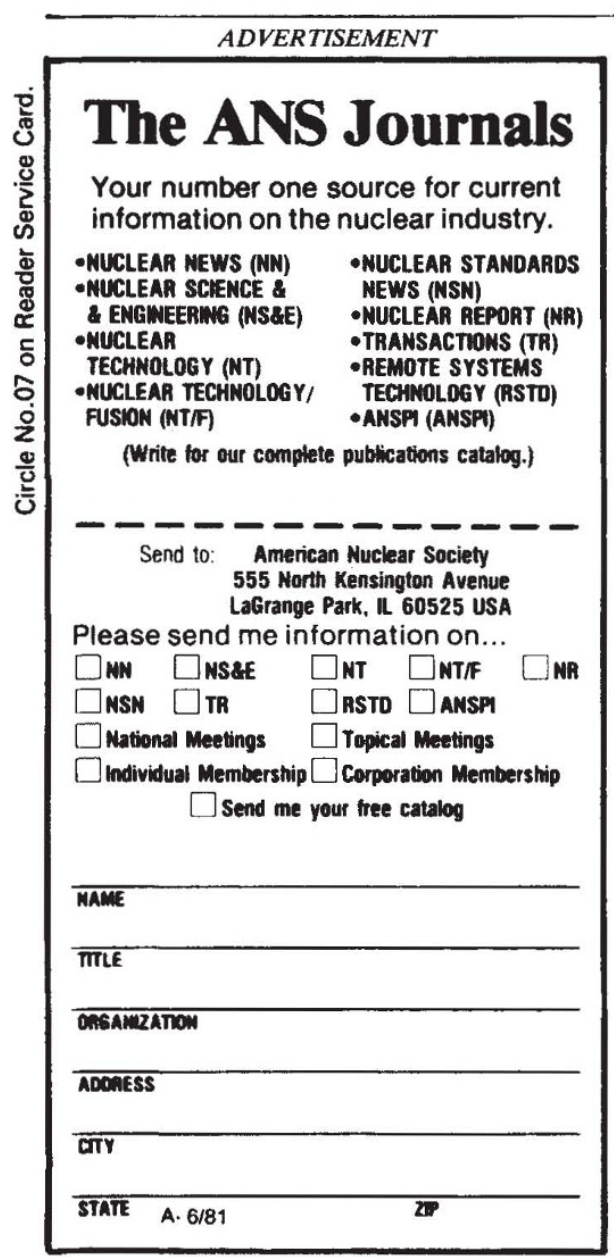

and the amount of snow deposited at the South Pole (p.270). Only if all such data are brought together, inconsistencies or contradictions resolved and accurate long time-series constructed, will we assemble a truly reliable account of past climates. Without this data bank - which, in current financial circumstances, remains a Utopian aim - it will be extremely difficult to document links with historical change, devise realistic policies or improve the efficiency of forecasting. Lamb has given us a comprehensive picture of where we stand now; unless we take his advice, and move on to a new level of understanding, both of the past and therefore of the future, the old joke will remain true for generations to come.

Theodore K. Rabb is a Professor of History at Princeton University. He is co-editor of Climate and History (Princeton University Press, 1982).

\title{
The ins and outs of sexual reproduction
}

\section{Mark Ridley}

Philopatry, Inbreeding, and the Evolution of Sex. By William M. Shields. Pp.245. Hbk ISBN 0-87395-617-6; pbk ISBN 0-87395-618-4. (State University of New York Press: 1982.) Hbk \$49, £39.20; pbk $\$ 16.95, £ 13.55$.

Philopatry, Inbreeding, and the Evolution of Sex is the latest answer to the question of why sexual reproduction exists. It is a long argument, drawn from many parts of evolutionary biology: Shields calls it a "teleonomic web", but, in the metaphor of zoological artefacts, it is more a bird's nest than a spider's web. He has selected sticks from the literature of population genetics, speciation, life histories and behaviour, added a few feathers of his own, and arranged them according to a most personal design.

Shields starts with philopatry (which means not moving far from place of birth to place of breeding). A philopatric species may be broken into many local, relatively inbred populations; this Shields turns round to say that inbreeding is the function of philopatry. He then examines the advantages and disadvantages of inbreeding, accepts the former, rejects the latter, and concludes that organisms inbreed much more than biologists have supposed.

The puzzle of sex is that asexual reproduction has two clear-cut advantages: it saves on males, and it propagates genes more efficiently. If a (dominant) mutant arises, causing its bearer to produce a proportion of its offspring asexually, the mutant will go into 50 per cent of the asexual offspring (for the gene is heterozygous when rare), compared with 25 per cent of its sexual offspring (after crossing with a wild-type homozygote). But those sexual offspring are now infected, and the sexual part of the population will gradually be taken over as further mutants, increasing the proportion of asexual offspring, arise and spread.

Such is the disadvantage of sex, but it assumes outbreeding. If there is inbreeding sex costs less. Under inbreeding (as W. D. Hamilton first noticed) sex ratios may be female-biased, which saves on males. In- breeding also protects a sexual population from genes for parthenogenesis: in the extreme case of self-fertilization, sexual reproduction becomes equivalent to asexual.

At this point, Shields could have stopped. It is widely accepted that sex is less costly with inbreeding, but not that inbreeding is common, so inbreeding would be an original answer to the question. But he goes further, and argues that sex with inbreeding is not just equivalent to parthenogenesis, but better than it. He draws on an argument which has come to be called Muller's ratchet. Here (as elsewhere) the case is inconclusive, not least as we find Shields confidently unaware that Muller's ratchet provides only a long-term, group selectionist advantage for sex.

Shields's main thesis, however, is that inbreeding is much more common than usually supposed. Biologists have been persuaded that inbreeding is exceptional by many observations of avoidance of inbreeding, by the manifestation of inbreeding depression (together with an explanation of why it exists) and by evidence that sex ratios are not usually female-biased. Shields does indeed take on all of these arguments, but he is not really stimulating. For instance, he denies the evidence for inbreeding depression because it has mainly come from laboratories. $\mathrm{He}$ also argues that inbreeding is advantageous because it speeds up the rate of evolution (which is group selectionist) and protects coadapted gene complexes (which are imaginary).

Although I think Shields is wrong, I would still recommend his book to its intended audience. It is confined, by its language (which reads like, say, the American Naturalist) to experts. They will find in it an original attempt to solve an important and unanswered question. And, even if the overall theory is wrong, perhaps someone will find a use for one or two of those feathers which Shields himself has contributed.

Mark Ridley is the Hayward Junior Research Fellow of Oriel College, Oxford University. 